\title{
Quality of life in morbid obesity
}

\author{
I. Poves Prim, G. J. Macías, M. Cabrera Fraga, L. Situ and C. Ballesta López \\ Surgical Bariatric Unit. Laparoscopic Center. Teknon Medical Center. Barcelona, Spain
}

\begin{abstract}
Introduction: morbid obesity (MO) is a chronic disease that is reaching epidemic proportions and becoming an increasing health problem in developed countries. Obesity-related comorbidities reduce both the quality and expectancy of life.

Objectives: to validate the GIQLI (Gastrointestinal Quality of Life Index) test as a reliable and effective tool for the evaluation of quality of life in morbidly obese patients.

Patients and methods: the GIQLI test is made up of 36 individually scored items, the addition of which give up a final score. A higher score correlates with a better quality of life. Items can be separated into five groups or dimensions: digestive symptoms, emotional status, effects of treatment, and physical as well as social dysfunction. The GIQLI test was administered to a randomized sample of 1990 morbidly obese patients who fulfilled the indication criteria for bariatric surgery, and to a control group of 100 healthy individuals with no known medical, functional or psychiatric disease. Overall test and specific dimension scores were evaluated for each group.

Results: overall test and specific dimension scores were significantly lower in patients with MO when compared to the control group. The overall GIQLI score decreased as age increased, as did the number of associated comorbidities.

Conclusions: the GIQLI test proved to be a rather useful tool to evaluate quality of life in morbidly obese patients. These patients present a poorer quality of life not only because of the presence of digestive symptoms but also because of their emotional, physical, and social status.
\end{abstract}

Key words: Morbid obesity. Quality of life. Bariatric surgery.

Poves Prim I, Macías GJ, Cabrera Fraga M, Situ L, Ballesta López C. Quality of life in morbid obesity. Rev Esp Enferm Dig 2005; 97: 187-195.

\section{Recibido: 25-05-04.}

Aceptado: 28-09-04.

Correspondencia: Ignasi Poves. Unidad de Cirugía Bariátrica de Centro Laparoscópico. Centro Médico Teknon. C/ Vilana, 12, Suite 148. 08022 Barcelona. Tel.: 933933 148. Fax: 933933 048.e-mail: poves@clb.es

\section{INTRODUCTION}

Morbid obesity (MO) is a chronic disease that is reaching epidemic proportions in developed countries (1). $\mathrm{Pa}$ tients with MO not only have a greater risk of suffering from serious associated diseases (cardiovascular, respiratory, metabolic, degenerative, etc.) and a shorter life expectancy, but also expect a poorer associated quality of life (2). The incidence of some digestive diseases, such as biliary lithiasis and gastroesophageal reflux disease, increases with obesity. The problem has reached such a magnitude that general unanimous consensus has been clearly established regarding the indication of bariatric surgery (3), which is currently considered the only effective treatment available to achieve adequate, sustained weight loss in morbidly obese patients $(4,5)$. The evaluation of health-related quality of life (HRQL) as used in the study digestive diseases $(6,7)$ has been steadily growing to include other conditions such as MO (8).

Current medicine not only calls for an evaluation of results in terms of cure for a given disease but also for an improvement in the quality of life and side effects resulting from every treatment. HRQL in morbidly obese patients -with or without comorbid diseases- cannot be based on the subjective perception of the physician but on objective, easy-to-assess parameters. Chronic diseases such as obesity affect HRQL and continuously limit the affected individual's daily activity. The objective measurement of HRQL enables a collection of additional information on a specific disease, and the evaluation of the impact of said disease on the patient and his or her setting.

Indexes used to evaluate HRQL must meet some basic criteria (9-11). There is a wide array of multiple questionnaires to measure HRQL, some of which are specific with other being more generic $(9,10)$. GIQLI (Gastrointestinal Quality of Life Index) is a validated questionnaire designed to measure quality of life in patients af- 
fected with digestive diseases. Its use also allows the clinician to evaluate the effectiveness and sequelae from different medical or surgical treatments in the short, mid and long run.

The objective of the study was to evaluate quality of life in morbidly obese patients by using the GIQLI questionnaire. This questionnaire will be subsequently validated for use as an effective tool for the evaluation of outcomes obtained with the various treatments used in MO, taking into account that in bariatric surgery the anatomy of the normal digestive system is modified.

\section{PATIENTS AND METHODS}

From May 2002 to October 2003, 190 patients suffering from severe or morbid obesity who were candidates for surgical treatment (MO group) were given a GIQLI questionnaire. The existence of comorbid diseases and/or functional alterations resulting from obesity was analyzed for each patient. During the same period of time the same survey was administered to a group consisting of a randomized sample of 100 individuals (control group). The control group included individuals without moderate to severe obesity, with a body mass index (BMI) below $30 \mathrm{~kg} / \mathrm{m}^{2}$, no known medical diseases or evident clinical manifestations, and no presence of sequelae derived from previous treatments or diseases, lack of neurosensorial defects or psychiatric diseases, and no alcohol or drug dependence. The subjects in the control group were recruited among the companions of patients who came to the practice to get a surgery consultation, either for obesity or other conditions. All surveys, including those in the control group and in the MO group, were anonymous. Incomplete surveys, poorly filled-out surveys, and unreliable surveys were all excluded from the study.

Obese patients who were candidates to bariatric surgery met the consensus criteria established in 1991 by the American Society of Bariatric Surgery (3): BMI above $40 \mathrm{~kg} / \mathrm{m}^{2}$ or above $35 \mathrm{~kg} / \mathrm{m}^{2}$ with associated comorbidities, failed hygienic-dietary treatment and/or drug treatment after one year, lack of endocrine pathology responsible for obesity, sufficient understanding and conformity on the part of the patient regarding the surgical procedure, no alcohol or drug dependence, acceptable operative risk, and age between 18 and 50 years (in our series no strict limit above said age was established). The group of obese patients who were candidates to bariatric surgery was subdivided into 3 groups according to BMI: pathological obesity $\left(\mathrm{BMI}<40 \mathrm{~kg} / \mathrm{m}^{2}\right)$, morbid obesity $\left(40-50 \mathrm{~kg} / \mathrm{m}^{2}\right)$, and super obesity $\left(>50 \mathrm{~kg} / \mathrm{m}^{2}\right)$ (Table IV).

The GIQLI questionnaire, which was created in 1994 by Eypasch et al. $(12,13)$ and then translated into Spanish and validated in year 2000 (14), was used to assess HRQL. The validated form is a mixed questionnaire including generic aspects of quality of life, as well as disease-specific aspects for symptoms of the upper and low- er gastrointestinal tract. It contains 36 items that can be grouped into 5 dimensions: 19 questions covering digestive symptoms (1 to 9 and 27 to 36 ), 7 questions on physical status (15 to 21 ), 5 questions on the emotional status (10 to 14$), 4$ questions on the social setting or surroundings (23 to 26), and one question on the effects of medical treatment (question number 22). Each of these 36 items is valued from best to worst (from 4 to 0 points), with 144 points being the maximum possible score for a healthy patient.

The dimension covering the physical status refers to the presence of tiredness, fatigue, general malaise or feeling unwell, insomnia, bothersome changes in physical appearance, energy level, endurance, and physical condition. The emotional dimension covers the degree of tolerance to daily stressful situations, presence of depression, nervousness, fear, satisfaction with life, and degree of frustration. The social setting focuses on the capacity of the individual to carry out daily activities, leisure and spare-time activities, as well as changes in the interactions with relatives and friends, and sexual life.

An analysis of variance (ANOVA) was used for statistical comparisons for overall results and subsets of the administered test, and to study differences in the lines of compared curves. For the comparative study of population characteristics (age and BMI) Student's t test was used. Differences were considered significant when $\mathrm{p}$ was $<0.05$.

\section{RESULTS}

Table I shows the population characteristics of the control group and the morbidly obese group. No significant differences were found between both populations with regard to mean age. No significant differences were found in the control group between genders with regard to population characteristics, age, BMI, or total GIQLI score. Between genders in the MO group there were no significant population differences (age and BMI). There were, however, significant differences in the final GIQLI score, which was lower in females.

Table II shows the GIQLI scores for both groups. The scores are presented as total figures or broken-down figures by dimensions or areas of dysfunction. GIQLI was greater in the control group than in the MO group, with

\begin{tabular}{|c|c|c|c|c|}
\hline & \multicolumn{2}{|c|}{ Control } & \multicolumn{2}{|c|}{ MO } \\
\hline & Men & Women & Men & Women \\
\hline e & $40.8 \pm 8.1$ & $39.6 \pm 11.4$ & $38.3 \pm 10.2$ & $40.4 \pm 11.9$ \\
\hline Al & $26.2 \pm 2.3$ & $24.3 \pm 2.6$ & $43.7 \pm 6.2$ & $43.4 \pm 7.1$ \\
\hline IlQLI & $118 \pm 8$ & $120 \pm 11$ & $94 \pm 15$ & $88 \pm 16$ \\
\hline
\end{tabular}


Table II. Results of GIQLI test (total and dimensions) for both control and morbid obesity (MO) groups

\begin{tabular}{lccc}
\hline & Control & MO & $p$ \\
\hline Digestive symptoms & $62.5 \pm 6.2$ & $57.9 \pm 7.8$ & $<0.05$ \\
Emotional & $14.1 \pm 2.9$ & $10.6 \pm 3.9$ & $<0.05$ \\
Physical & $23.3 \pm 3.7$ & $9.2 \pm 5$ & $<0.05$ \\
Social & $14.2 \pm 2$ & $9.1 \pm 3.6$ & $<0.05$ \\
Total & $118.4 \pm 10.7$ & $89.3 \pm 16$ & $<0.05$ \\
\hline
\end{tabular}

significant differences both in the total score as well as in all the other areas (physical, digestive symptoms, emotional status, and social situation). The "medical treatment" dimension was not analyzed in this paper, as there was just one related question.

In the group of obese patients, $40 \%$ were superobese $\left(\mathrm{BMI} \geq 50 \mathrm{~kg} / \mathrm{m}^{2}\right), 47 \%$ were morbidly obese with a BMI of $40-50 \mathrm{~kg} / \mathrm{m}^{2}$, and $13 \%$ suffered from grade-III pathological obesity $\left(\mathrm{BMI}<40 \mathrm{~kg} / \mathrm{m}^{2}\right)$ with associated comorbid conditions. Mean GIQLI scores were 84.7 (SD 17.6), 90.2 (SD 16.4) and 90.7 (SD 14), respectively, for these groups of obese patients (Table III). There were no significant differences concerning total GIQLI score between patients with super-obesity or with pathologicalmorbid obesity $(p=0.07)$. In relation to the different dimensions of the questionnaire, there were in fact significant differences to the detriment of the superobese group in the physical and social dimensions.

Table III. Population features and results of GIQLI test in morbid obesity and its grades: pathologic obesity (PO), morbid obesity (MO) and super-obesity (SO)

\begin{tabular}{lccc}
\hline & $\begin{array}{c}P O \\
(n=62)\end{array}$ & $\begin{array}{c}\text { MO } \\
(n=90)\end{array}$ & $\begin{array}{c}\text { SO } \\
(n=38)\end{array}$ \\
\hline Age & $39 \pm 10$ & $39.5 \pm 11.6$ & $42.5 \pm 13.5$ \\
Gender (\% M / W) & $22 / 78$ & $30 / 70$ & $20 / 80$ \\
BMl & $36.7 \pm 1.9$ & $43.8 \pm 2.9$ & $54 \pm 5.7$ \\
Digestive symptoms & $57.3 \pm 7.3$ & $58.7 \pm 7.6$ & $57 \pm 9.2$ \\
Emotional & $10.5 \pm 3.2$ & $10.7 \pm 4.2$ & $10.5 \pm 4.3$ \\
Physical & $10.5 \pm 4.8$ & $9.1 \pm 4.9$ & $7.3 \pm 4.8$ \\
Social & $9.7 \pm 3.2$ & $9.3 \pm 3.6$ & $7.6 \pm 4$ \\
Total score & $90.5 \pm 13.8$ & $90.3 \pm 16.6$ & $84.7 \pm 17.6$ \\
\hline
\end{tabular}

In the group of obese patients, 2, 42, 34, 16, 4.6 and $1.4 \%$ of subjects had none, one, two, three, four or five associated comorbid conditions. Figure 1 shows the significant progressive decrease in final GIQLI score depending on the number of comorbid conditions of the obese patient.

Figure 2 represents the variation in GIQLI score of obese patients $v s$. the control group depending upon age. Both scores decrease significantly as age increases. No significant differences were found between both lines of the curve.

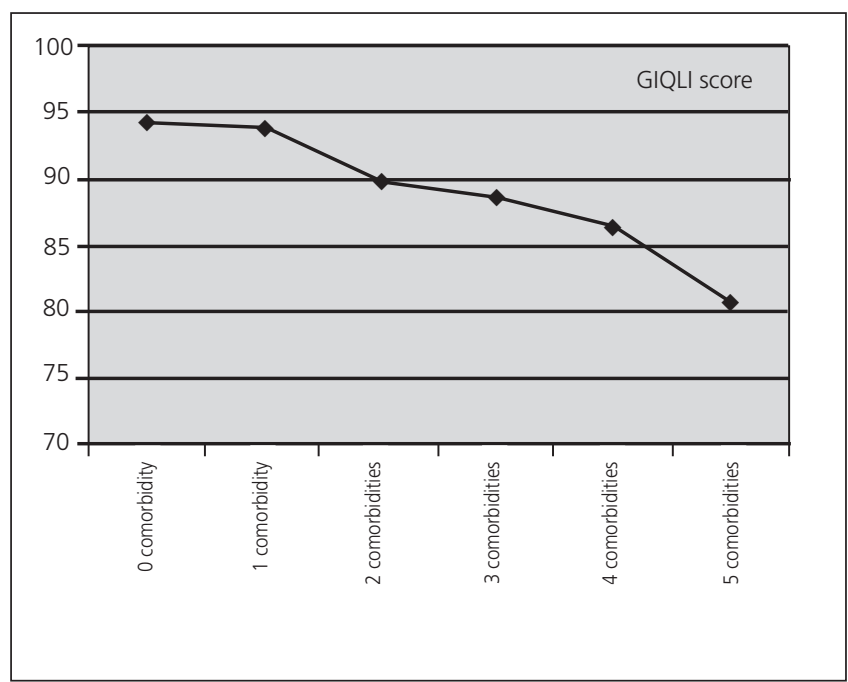

Fig. 1.- GIQLI score attending to associated comorbidity. Puntuación GIQLI según comorbilidad asociada a la obesidad.

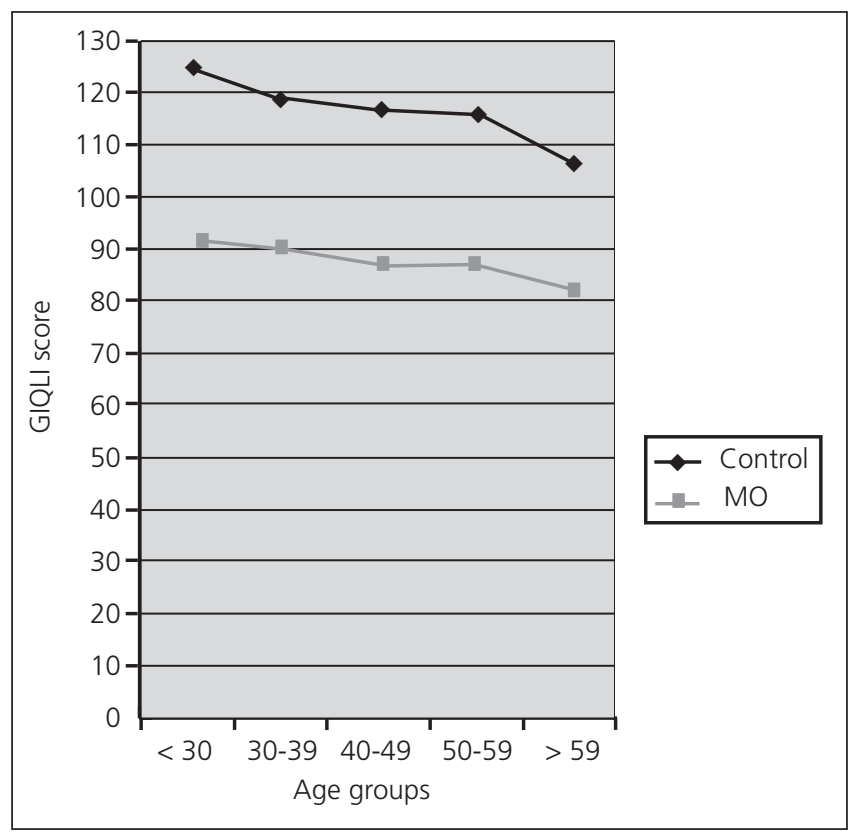

Fig. 2.- Evolution of GIQLI score in both control and morbid obesity groups attending to age.

Evolución de la puntuación GIQLI en los grupos control y obesidad mórbida según la edad.

\section{DISCUSSION}

The health status of a population, the disability caused by a disease, and the relief brought about by treatment is no longer assessed solely using epidemiological quantitative data as interpreted by healthcare personnel. The selfperspective a patient has of his or her own health bears great transcendence on all dimensions (physical, mental, and social) (18). To this end, tools to measure HRQL have started to be developed (19). There are questionnaires considered generic (20-23) that have proven useful 
for the assessment of any disease or health status, and other have been specifically created for assessing specific diseases. The GIQLI questionnaire is capable of providing information on generic as well as on specific aspects of digestive symptoms and quality of life. For this reason, GIQLI has been extensively used in different pathologies and to evaluate medical treatments or surgical procedures performed on the digestive tract (14).

Other specific questionnaires for the assessment of obesity, such as the IWQoL (Impact of Weight on Quality of Life Scale), SOS (Swedish Obese Subjects) or HRQoL + HSP (Health Related Quality of Life + Health State Preference), have demonstrated a good capacity to assess the repercussion that side effects derived from obesity have on the quality of life of these patients. The BAROS (Bariatric Analysis Reporting Outcome System) (24) evaluates the effects of bariatric surgery on the quality of life of the obese patient. In Spain, it has been possible to adapt and validate generic HRQL questionnaires (25-28), many of which have been administered to obese patients $(2,29)$. Nevertheless, no studies have been conducted so far to evaluate quality of life in these patients that could at the same time be used to correlate changes occurring in these patients following bariatric surgery (30). Given that bariatric surgery, in any of its techniques, modifies the anatomy and the normal functionality of the digestive tract, in our opinion the GIQLI questionnaire can be a very valuable tool to measure the patient's perception of his or her quality of life, mainly in relation to digestive discomfort and other possible side effects caused by the different surgical techniques. For this reason, it would be advisable to validate the GIQLI questionnaire as a study and assessment tool in MO.

The GIQLI questionnaire has been used to assess quality of life in morbidly obese patients because it affords the following advantages:

-It provides information on the quality of life of the patient in relation to both generic aspects (physical status, social relations, emotional status) and specific aspects of the upper and lower digestive tract.

- It is widely used because it is a self-contained, easyto-understand and easy-to-complete questionnaire that does not require a lot of time to fill in the data.

- It thoroughly assesses the changes in the quality of life of an obese patient who has undergone bariatric surgery (due to the changes caused in the intestinal tract by this sort of surgery).

Other authors have demonstrated its value as a measurement tool for HRQL in obese patients (15-17).

The results obtained via questionnaires on the quality of life of morbidly obese patients, such as GIQLI, must be interpreted very cautiously due to a bias in the selection process. It is difficult to assess whether morbidly obese patients who were given the questionnaire showed more concern about their obesity than other obese patients, as they came to the practice with the intention of finding a definitive solution - surgery in this case. According to some authors (31), such concern could reflect a greater psy- chopathological component (anxiety and/or depression), a more severe or incapacitating case of obesity, or a case of obesity associated with increased risk for and a higher number of comorbidities associated with such obesity, as compared to the rest of the general obese population.

Both study samples (control group and MO) were comparable, as no significant differences were found regarding age; while it is true that an unbalance existed with regard to gender, no significant differences were found in relation to age, BMI or GIQLI score between males and females.

Some studies on public health have shown gender to have an influence on the way an individual perceives his or her health. In males, the perception of health with regard to their obesity would decrease with age, in sharp contrast with the worst perception of females, especially in young obese women (32). In our study we found no significant differences in quality of life between both genders in the control group. However, significant differences were in fact found with regard to the quality of life in the MO group, with the perception of life being worse in women than in men. These differences are more evident in the emotional dimension of the test, with no significant differences found neither in the physical nor in the social dimensions or with regard to digestive symptoms. These findings could mean that women with MO would be more emotionally labile than men, and that such feelings would transpire in their daily life thus causing more stress, anxiety, depression, and frustration.

According to our results, total GIQLI score was significantly lower in the group of patients with MB than in the control group. The score obtained in the control group of the study was similar to that obtained in the control group in the original study by Eypasch et al. $(12,13)$ for validation of the GIQLI questionnaire. The group of healthy patients studied by the above-mentioned authors coincides demographically with our control group, both in age and gender. This similarity would confirm the adequate interpretation and completion of the questionnaire on the part of the population cared for and its validation.

An overall decrease in GIQLI score has been observed for all dimensions. Morbidly obese patients have a worse perception of their quality of life versus patients in the control group. This worse quality of life is the result of a marked alteration of digestive specific symptoms related to obesity, coupled with a worsening of physical, emotional and social status in the morbidly obese patient.

Using other questionnaires, both generic such as Fontaine and Barlett with the SF-36 (33) and Kolotkin et al. $(25,34)$ with the IWQoL, or specific such as Suvillan with the SOS (36), other authors have obtained the same results. All these authors refer to the impact that HRQL has on areas such as the patient's level of energy, social ability, role limitations due to emotional problems, and mental health, self-esteem and sexual life.

According to some authors, obesity, being a chronic, systemic condition, has a strong repercussion not only on 
the different organs and systems of the patient's body (degenerating effects) but also on the psychological and social dimensions, as these patients often suffer from damaged self-esteem, depressed mood, emotional lability, higher anxiety, feelings of guilt, self-recrimination, and a deep feeling of frustration resulting from continued failure to achieve "ideal" weight standards despite great efforts to lose weight $(37,38)$.

The GIQLI questionnaire has been shown to be a reliable and valid questionnaire to measure quality of life in morbidly obese patients. Morbidly obese patients have a worse perception of life than non-obese patients. Such deterioration in quality of life can be attributable to excessive body weight and the existence of comorbid conditions caused by obesity. This worsening in quality of life is justified not only by a greater, obvious limitation of their physical condition (physical dimension) but also by a worse perception of the accompanying digestive symptomatology, the patient's social attitude (social dimension), and his or her mind frame (emotional dimension). Since the GIQLI questionnaire bears an important specific weight on the evaluation of the way a patient perceives his or her digestive symptoms, it can be a very useful tool in the assessment of the final outcome and side effects of bariatric surgery.

\section{REFERENCES}

1. Mokdad AH, Bowman BA, Ford ES, Vinicor F, Marks JS, Koplan JP The continuing epidemics of obesity and diabetes in the United States. JAMA 2001; 286: 1195-200.

2. Barajas MA, Robledo E, Tomás N, Sanz T, García P, Cersada I. Quality of life in relation to health and obesity in a primary care center. Rev Esp Salud Publica 1998; 72: 221-31.

3. Gastrointestinal surgery for severe obesity: National Institutes of Health Consensus Development Conference Statement. Am J Clin Nutr 1992; 55: 615S-9S.

4. Monteforte MJ, Turkelsoft CM. Bariatric surgery for morbid obesity. Obes Surg 2000; 10: 391-401.

5. Sjostrom L. Surgical intervention as a strategy for treatment of obesity. Endocrine 2000; 13: 213-30.

6. Casellas F, López Vivancos J, Malagela JR. Previous experience and quality of life in patients with inflammatory bowel disease during relapse. Rev Esp Enferm Dig 2003; 95: 476-9, 471-5.

7. Mones Xiol J. Quality of life. Can it really be measured? Rev Esp Enferm Dig 2000; 92: 349-53.

8. Testa MA, Simonson DC. Assessment of quality - of - life outcomes. N Engl J Med 1996; 334: 835-40.

9. Eisen GM, Locke GRIII, Provenzale D. Health related quality of life, a prime for gastroenterologists. Am J Gastroenterol 1999; 94: 2017-21.

10. Yacarone RF, Locke GR III, Provenzale DT, Eisen GM. Quality of life measurent in gastroenterology: what is available? Am J Gastroenterol 2001; 96: 285-97.

11. Guyatt GH, Kishner B, Jaeschke R. Measuring Health status: what are the necessary measurement properties? J Clin Epidemiol 1992; 45: 1341-5.

12. Eypasch E, Williams JI, Wood-Dauphinee S, Ure BM, Schmulling C, Neugebauer E, et al. Gastrointestinal Quality of Life Index. Development, validation and application of a new instrument. Br J Surg 1995; 82: 216-22.

13. Eypasch E, Wood-Dauphinee S, Williams JI, Ure B, Neugebauer E, Troidl H. The Gastointestinal Quality of Life Index. A clinical index for measuring patient status in gastroenterologic surgery. Chirurg 1993; 644: 264-74.

14. Quintana JM, Cabriada J, López de Tejada I, Varona M, Oribe V, Bar- rios B, et al. Translation and validation of the Gatrointestinal Quality of Life Index (GICLI). Rev Esp Enferm Dig 2001; 93: 693-9.

15. Lee WJ, Yu PJ, Wang W, Lin CM, Wei PL, Huang MT. Gastrointesinal quality of life following laparoscopic vertical banded gastroplasty. Obes Surg 2002; 12: 819-24.

16. Arcila D, Velázquez D, Gamino R, Sierra M, Salin-Pascual R, González-Barranco J, et al. Quality of life in bariatric surgery. Obes Surg 2002; 12: 661-5.

17. Freys SM, Tigges H, Heimbucher J, Fuchs KH, Fein M, Thiede A. Quality of life following laparoscopic gastric banding in patients with morbid obesity. J Gastrointest Surg 2001; 5: 401-7.

18. Patrick DL, Erickson P. What constitutes quality of life? Concept and dimensions. Clin Nutr 1998, 7: 53-63.

19. Patrick DL, Beregner M. Measurement of health status in the 1990s. Annu Rev Public Health 1990; 11: 165-83

20. Bergener M, Robbitt RA, Carter WB, et al. The sickness impact profile. Development and final revision of a health status measure. Med Care 1981; 29: 787-805.

21. Ware JE Jr., Sherbourne CD. The MOS 36-ítem short-form health survey (SF-36). I. Conceptual frame work and item selection. Med Care 1992; 30: 473-83.

22. Mc Ewen J, Mc Kenna SP. Nottingham Health Profile. In: Spilker B, ed. Quality of Life and pharmacoeconomics in clinical trial. 2nd ed. Philadelphia: Lippincott- Raven, 1996. p. 281-6.

23. Naughton MJ, Shumaker SA, Anderson RT, et al. Psychological aspect of health related quality of life measurement. Test and scales. In: Spilker Bied. Quality of Life and pharmacoeconomics in clinical trials. 2nd ed. Philadelphia: Lipincott-Raven, 1996. p. 117-31.

24. Oria HE, Moorehead MK. Bariatric Analysis and Reporting Outcome System (BAROS). Obes Surg 1998; 8: 487-99.

25. Badia X, Gutiérrez F, Wiklund I, Alonso J. Validaty and raliability of the Spanish version of the Psychological General Well-Being Index. Qual Life Res 1996; 5: 101-8.

26. Alonso J, Prieto L, Antó JM. The Spanish version of the Notthingham Health Profile: a review of adaptation and instrument characteristics. Qual Life Res 1994; 3: 385-93.

27. Badia X, Alonso J. Adaptación de una medida de la disfunción relacionada con la enfermedad: la revisión española del Sickness Impact Profile. Med Clin 1994; 102: 90-5.

28. Alonso J, Prieto L, Antó JM. La versión española del SF-36 health survey: un instrumento para al medida de los resultados clínicos. Med Clin 1995; 104: 771-6.

29. López-García E, Banegas JR, Gutiérrez-Fisac JL, Perez-Regadera AG, Ganan LD, Rodríguez-Artalejo F. Relation between body weight and health-related quality of life among the elderly in Spain. Int J Obes Relat Metab Disord 2003; 27: 701-9.

30. Carbajo Caballero MA, Martín del Olmo JC, Blanco Álvarez JI, Cuesta de la Llave C, Martín Acebes F, Toledano Trincado M, et al. Vertical ring gastroplasty (VRG) in the treatment of the serious clinical obesity. Results and complications. Rev Esp Enferm Dig 1998; 90: 545-52.

31. Stolley MR, Kirschenbaun DS. Obese people who seek treatment have different characteristics than those who do not seek treatment. Health Psychol 1993; 12: 342-5.

32. Seidell JC, Bakx KC, Deurenberg R, Burema J, Hautvast JG, Huygen FJ. The relation between averwieght and subjetive health according to age, social class, slimming behavior and smoking habits in Dutch adults. Am J Public Health 1986; 76: 1410-5.

33. Fontaine KR, Batlett SJ. Estimating Health-Related Quality of Life in Obese individuals. Dis Manage Health Outcomes 1998; 3: 61-70.

34. Kolotkin RL, Head S, Hamilton M, Tse CK. Assessing impact of weight on quality of life. Obes Res 1995, 3: 49-56.

35. Kolotkin RL, Head S, Brookhart A. Construct validity of the impact of weight on quality of life. Obes Res 1997; 5: 434-41.

36. Sullivan M, Karlsson J, Sjostrom L, Backman L, Bengtsson C, Bouchard C, et al. Swedish Obese Subjets (SOS) - an intervention study of obesity. Baseline evaluation of health and psychosocial functioning in the first 1743 subjets examined. Int J Obes Relat Metab Disord 1993; 17: 503-12.

37. López de la Torre Casares M. Obesity and quality of life. Nutr Hosp 1999; 14: 177-83.

38. Mardomingo MJ, Psicopatología de la obesidad. En: Moreno B, Moreno, S, Álvarez J, eds. Obesidad: presente y futuro. Madrid: Grupo Áula Médica SA, 1997. p. 105-14. 